\title{
Association of Upregulated HMGB1 and c-IAP2 Proteins With Hepatocellular Carcinoma Development and Progression
}

\author{
Man Ru Bi ${ }^{1}$; Li Ying Zhu ${ }^{2}$; Bing Zhu Yan ${ }^{1}$; Li Yan Chen ${ }^{1}$; Fu Xiang Wang ${ }^{2}$; Ying Ji Ma ${ }^{2, *}$; Bao \\ Shan Yang ${ }^{1, "}$ \\ ${ }^{1}$ The Second Clinical Medical College, Harbin Medical University, Harbin, China \\ ${ }^{2}$ The Fourth Clinical Medical College, Harbin Medical University, Harbin, China \\ *Corresponding Authors: Ying Ji Ma, The Fourth Clinical Medical College, Harbin Medical University, Harbin 150001, China. Tel: +86-45182576842, Fax: +86-45182576842, E-mail: \\ 1633684215@qq.com; Bao Shan Yang, The Second Clinical Medical College, Harbin Medical University, Harbin 150001, China. Tel: +86-45186297509, Fax: +86-45186297509, E-mail: \\ baoshanyang@126.com
}

Received: September 12, 2014; Revised: November 20, 2014; Accepted: November 29, 2014

\begin{abstract}
Background: Hepatocellular carcinoma (HCC) is one of the most important health problems in China.
Objectives: This study analyzed expression of high-mobility group protein B1 (HMGB1) and inhibitor of apoptosis protein-2 (c-IAP2) proteins in HCC compared to paired para-tumor tissue samples to assess the association with HCC pathogenesis and progression.

Materials and Methods: Sixty-eight HCC and para-tumor tissue samples were collected for Western blot, qRT-PCR and immunohistochemical analyses of HMGB1 and c-IAP2.

Results: HMGB1 and c-IAP2 proteins were highly expressed in HCC tissue samples [85.3\%(58/68) and 82.4\% (56/68), respectively] compared to para-tumor tissue samples [32.3\% and 27.9\%, respectively]. Furthermore, expression of HMGB1 was significantly associated with enhanced c-IAP2 expression in HCC tissue samples $(\mathrm{r}=0.878, \mathrm{P}<0.01)$. Expression of HMGB1 was associated with tumor multiplicity and size, alphafetoprotein (AFP) level and advanced TNM stage, while expression of c-IAP2 was associated with tumor size, AFP level and advanced TNM stage.

Conclusions: Expression of HMGB1 and c-IAP2 proteins was associated with HCC development and progression, and the expression of HMGB1 and c-IAP2 proteins in HCC were significantly associated with each other. Additionally, these proteins may show promise as biomarkers to predict HCC progression.
\end{abstract}

Keywords:Hepatocellular Carcinoma; HMGB1; c-IAP2 Protein; Biomarkers

\section{Background}

Hepatocellular carcinoma (HCC) is the fifth most common cancer and the third most frequent cause of death of cancer in the world (1-3). Most HCC cases are diagnosed in advanced stage of disease, limiting the options of treatment. While liver transplantation offers improved survival, other treatments such as chemotherapy, may also help to control disease progression. Outcome of patients with HCC is poor (4). Furthermore, the main risk factors of HCCs are infection with hepatitis B or C, alcoholism, consumption of aflatoxin-contaminated food, liver cirrhosis and type II diabetes. Therefore, the importance of these risk factors varies widely; for example, in countries like China where hepatitis B is endemic (5), hepatitis B is the predominant cause of HCC. Whereas in countries, such as the US, the major cause of HCC is cirrhosis and alcoholism (6). Early detection of HCC and elimination of risk factors could reduce HCC-related mortality. For early HCC diagnosis or predicting disease progression, we need to understand molecular mechanism and pathogenesis of HCC. HCC development like any other cancer occurs because of silence of tumor suppressor genes or activation of oncogenes. These risk factors individually or together alter gene expression or mutation to cause hepatocytes to replicate at a higher rate and/or resistance to apoptosis, and in turn transform normal hepatocytes to HCC, although the precise mechanism remains to be defined $(1,7,8)$.

Our research focused on high-mobility group box 1 (HMGB1) in HCC. HMGB1 is an evolutionarily conserved, chromatin-binding protein. Altered HMGB1 expression could lead to tumor cell survival, expansion and metastasis (9), and overexpression of HMGB1 has been associated with all of central hallmarks of cancer (9-11). HMGB1 is secreted or released by necrotic cells, activated macrophages, mature dendritic cells and natural killer cells and functions to promote cell migration, differentiation, systemic inflammation and immunity (12-14). Nucleus-expressed HMGB1 protein integrates and stabilizes the nucleosome $(15,16)$, also facilitates DNA organization and regulation of gene transcriptional activation $(10,11)$. The nuclear localization of HMGB1 protein is regulated by posttranslational modifications, hyperacetylation

Copyright ( 2014, Kowsar Corp. This is an open-access article distributed under the terms of the Creative Commons Attribution-NonCommercial 4.0 International License (http://creativecommons.org/licenses/by-nc/4.0/) which permits copy and redistribute the material just in noncommercial usages, provided the original work is properly cited. 
on lysine residues, which induces HMGB1 to translocate from the nucleus to the cytosol (9). Previous studies have reported that HMGB1 protein is upregulated in different types of cancer, such as breast cancer $(17,18)$, melanoma $(19,20)$, gastric cancer (21), non-Hodgkin lymphoma (22), colorectal cancer $(23,24)$ and liver cancer $(25-27)$ and HMGB1 expression is associated with cancer invasion and metastasis. Therefore, HMGB1 is believed to be an oncogene in different cancers $(12-14,16,28)$. Previous studies have shown that overexpression of HMGB1 induced NF-kB activity, thereby leading to overexpression of inhibitor of apoptosis protein-2 (c-IAP2), a target gene of NF-kB $(23,29)$. C-IAP2 is a key antiapoptotic factor and overexpressed in a variety of human cancers, which is associated with drug resistance and cancer recurrence. c-IAP2 is a potent antiapoptotic factor, which inhibits apoptosis through its interaction with a variety of cytokines (30). c-IAP2 directly associates with caspase-3,-7 and -9 to attenuate apoptotic signal transduction, thereby inhibiting the incidence of apoptosis and promoting tumorigenesis $(13,14,31,32)$. A previous study hypothesized that HMGB1 acts as an oncoprotein to inhibit tumor cell apoptosis (33).

\section{Objectives}

In this study, we analyzed expression of HMGB1 and cIAP2 levels in HCC tissue specimens, and then assessed the prognostic significance of HMGB1 and c-IAP2 proteins in patients with HCC.

\section{Materials and Methods}

\subsection{Patients and Specimens Tissues}

To detect the level of HMGB1 and c-IAP2 mRNA and protein in paired tumor and para-tumor tissue samples (defined as $\geq 3 \mathrm{~cm}$ distance from the tumor edge), we collected fresh tissues from 68 patients with HCC who underwent hepatectomy between May 2011 and May 2013 from the Second and Third Clinical Medical College of Harbin Medical University (Harbin, China). Diagnosis of HCC in all patients was confirmed by histopathologic examination and no tumor cells were found in para-cancerous tissue samples. Complete clinicopathological data from each patient was collected and surgical specimens were processed immediately after resection. The specimens were frozen in liquid nitrogen and transferred to a $-80{ }^{\circ} \mathrm{C}$ freezer or fixed in $4 \%$ formalin followed by paraffin embedding. This study was approved by the medical ethics committee of the Second Affiliated Hospital of Harbin Medical University. All participants provided their written informed consent before participation.

\subsection{Immunohistochemistry}

Expression of HMGB1 and c-IAP2 proteins in paired tumor and para-tumor tissue samples of 68 patients was examined by immunohistochemistry. The samples were fixed by $4 \%$ buffered formalin, embedded in paraffin and cut into $4 \mu \mathrm{m}$-thick sections. The sections were then baked at $70{ }^{\circ} \mathrm{C}$ overnight, and de-waxed in xylene and rehydrated in a graded concentration of ethanol and washed with phosphate buffered saline (PBS). The sections were then subjected to antigen retrieval in a high pressure cooker with a citric acid buffer and slowly cooled to room temperature. After, sections were incubated in $3 \% \mathrm{H}_{2} \mathrm{O}_{2}-$ methanol for 10 minutes, then incubated overnight at $4{ }^{\circ} \mathrm{C}$ with a rabbit polyclonal antibody against human HMGB1 at a dilution of 1:40 (Boster Biological Technology Co., Ltd., Wuhan, China) or a mouse polyclonal antibody against human c-IAP2 at a dilution of 1:10 (German R\&D company), respectively. Subsequently, tissues were treated with horseradish peroxidase conjugated secondary antibody (Zhongshan Jinqiao Biotechnology Co., Ltd, Beijing, China), and the color was developed using diaminobenzidine tetrahydrochloride (DAB) and counterstained with hematoxylin. A known HMGB1 positive liver cancer specimen was used as a positive control, while in negative control samples the antibody was replaced by PBS.

\subsection{Review and Scoring of Immunostained Sections}

Immunostained sections were reviewed and scored under a light microscope (Shanghai optical instrument factory, Shanghai, China) by two independent investigators (Bi MR and Chen LY), blinded to the treatment group. To score expression of HMGB1 and c-IAP2 protein, 10 microscopic fields $(\times 400)$ were randomly selected and evaluated for the proportion of positive cells and staining intensity. We ranked the staining scores into four categories: 1 , $\leq 25 \%$, as no staining/background of negative controls $(-) ; 2,26-50 \%$, as weak staining (+); 3, 51-75\%, as moderate staining (++); and $4,76-100 \%$, as intense staining (+++). We defined $(-),(+)$ as low expression and $(++)$ and $(+++)$ as overexpression.

\subsection{Protein Extraction and Western Blot}

A hundred milligram of fresh tissue was grounded into powder in liquid nitrogen and $400 \mu \mathrm{L}$ lysis buffer (50 mmol/L Tris- $\mathrm{HCl}$ at $\mathrm{pH} 7.4,150 \mathrm{mmol} / \mathrm{L} \mathrm{NaCl}, 1 \%$ TritonX-100, $1 \mathrm{mmol} / \mathrm{L}$ PMSF, $1 \mathrm{mmol} / \mathrm{L}$ EDTA, and $0.25 \%$ sodium deoxycholate) was added to the sample. The mixtures were then centrifuged at $12000 \mathrm{rpm}$ and $4{ }^{\circ} \mathrm{C}$ for 10 minutes and one-fifth volume of $5 \times$ Laemmli's sample buffer ( $62.5 \mathrm{mM}$ Tris base, 10\% (w/v) glycerol, 2.3\% sodium dodecyl sulphate, and 5\% 2-mercaptoethanol) was added to the supernatant. After denaturing at $95{ }^{\circ} \mathrm{C}$ in a water bath, protein samples were quantified and separated by $12 \%$ sodium dodecyl sulfate-polyacrylamide gel electrophoresis (SDS-PAGE) and transferred to a PVDF membrane (Millipore, Schwalbach, Germany). After blocking with $5 \%$ non-fat milk for two hours at room temperature, membranes were incubated overnight at $4{ }^{\circ} \mathrm{C}$ with an anti-HMGB1 antibody at a dilution of 1:400 (Boster Bio- 
Bi MR et al.

logical Technology), anti-c-IAP2 antibody at a dilution of 1:200 (German R \& D) or anti- $\beta$-actin antibody at a dilution of 1:800 (Santa Cruz Biotechnology, Heidelberg, Germany). Followed by incubation with an antimouse or rabbit horseradish peroxidase conjugated IgG (Zhongshan Jinqiao Biotechnology, Beijing, China). The membranes were incubated with an ECL western blotting detection system (Zhongshan Jinqiao Biotechnology) for autoradiography against X-ray films (Zhongshan Jinqiao Biotechnology).

\subsection{RNA Isolation and Quantitative Reverse Tran- scriptase Polymerase Chain Reaction}

Total RNA was isolated from tumor and para-tumor tissue samples using a TRIzol reagent (Invitrogen, Carlsbad, CA) according to the manufacture's instruction. RNA samples of $0.5 \mu$ g were reversely transcribed into cDNA using a reverse transcriptase and the cDNA samples were amplified by qPCR using TaqMan fluorescent probes (Ambion, Austin, TX, USA) for HMGB1 (5'-ATATGGCAAAAGCGGACAAG-3' and 5'-GCAACATCACCAATGGACAG-3'), c-IAP2 (5'-TCCGTCAAGTTCAAGCCAGTT-3' and 5'-TCTCCTGGGCTGTCTGATGTG-3'), or $\beta$-actin (5'-GCGGGAAATCGTGCGTGACATT-3' and 5'-GATGGAGTTGAAGGTAGTTTCGTG-3'). PCR conditions were an initial $95^{\circ} \mathrm{C}$ for 10 minutes, 40 cycles of $95^{\circ} \mathrm{C}$ for 15 seconds and $60^{\circ} \mathrm{C}$ for one minute. In the last PCR cycle, during the temperature rise from $55^{\circ} \mathrm{C}$ to 95 ${ }^{\circ} \mathrm{C}$, the melt curves were collected at $0.5{ }^{\circ} \mathrm{C}$ intervals. Each experiment was performed in duplicate, repeated three times and the mean fold-change in HMGB1 and c-IAP2 mRNA levels was calculated using the $2^{\triangle \triangle \mathrm{Ct}}$ method.

\subsection{Statistical Analysis}

All data were presented as mean \pm standard deviation (SD) of the results obtained from three independent experiments. Comparison between the two groups was performed using student's t-test for continuous data and chi-square test for categorical data. Differences between each group were assessed by spearman's rank correlation. $\mathrm{P}<0.05$ was considered statistically significant. All data were analyzed using SPSS version 13.0 statistical software (SPSS, Chicago, IL, USA).

\section{Results}

\subsection{Increased Expression of HMGB1 and c-IAP2 Pro- teins in HCC Tissues}

Immunohistochemistry results showed that HMGB1 protein was highly expressed in tumor tissue samples compared to para-tumor tissue samples (85.3\% vs. 32.3\%, $\chi^{2}=46.10, \mathrm{P}<0.01$; Table 1). As shown in Figure 1 A, strong staining of HMGB1 was observed in the cytoplasm and weaker staining was observed in the nuclei of tumor cells, resulting in high expression of HMGB1 protein in tumor tissue samples in 44 of 68 HCC cases (64.7\%; Table 1 ).
In Figure $1 \mathrm{~B}$, only 22 of 68 HCC cases displayed expression of HMGB1 in paired para-tumor tissue samples (32.3\%; Table 1), among which 11 cases showed weak staining in the cytoplasm and nuclei of paired para-tumor cells. Furthermore, immunohistochemistry results showed that expression of c-IAP2 protein was significantly higher in HCC tissue samples compared to para-tumor tissue samples (82.4\% vs. 27.9\%, $\chi^{2}=46.335, \mathrm{P}<0.01$; Table 1 ). There was strong staining of c-IAP2 protein in the cytoplasm of 38 (55.9\%) HCC cases (Figure 1 C, Table 1), whereas only 19 of $68(27.9 \%)$ of paired para-tumor tissue samples expressed C-IAP2 protein. Overall, there was only one case that demonstrated a strong expression of c-IAP2 protein in paratumor tissue samples (Figure 1 D, Table 1). Furthermore, we verified our immunohistochemical results in HCC and para-tumor tissue samples using Western Blot, and the data was consistent with the immunohistochemical results, i.e. 59 of 68 HCC cases showed significant high expression of HMGB1 protein in HCC tissue samples (T) compared to paired para-tumor $(\mathrm{P})$ tissue samples (Figure 2 A). Besides, 54 of 68 HCC cases showed significant high c-IAP2 expression in tumor tissue samples (T) compared to paired para-tumor $(\mathrm{P})$ tissue samples (Figure 2 $\mathrm{B})$. The difference between relative expression levels of HMGB1 and c-IAP2 in tumor and para-tumor samples was statistically significant $(\mathrm{P}<0.01)$.

\subsection{Association of HMGB1 and c-IAP2 Expression With Clinicopathological Data of HCC Patients}

We associated expression of these two proteins with clinicopathological data from HCC patients. We found that expression of HMGB1 was significantly associated with tumor multiplicity $\left(\chi^{2}=4.225, \mathrm{P}<0.05\right)$, tumor size $\left(\chi^{2}=10.748, \mathrm{P}<0.05\right)$, alpha fetoprotein (AFP) level $\left(\chi^{2}=\right.$ 4.83, $\mathrm{P}<0.05)$ and advanced TNM stage $\left(\chi^{2}=7.0584, \mathrm{P}<\right.$ $0.05)$, while high expression of c-IAP2 was significantly associated with tumor size $\left(\chi^{2}=9.862, \mathrm{P}<0.05\right)$, AFP level $\left(\chi^{2}=9.998, \mathrm{P}<0.05\right)$, and advanced TNM stage $\left(\chi^{2}=8.228\right.$, $\mathrm{P}<0.05$; Table 2). However, there was no significant association between expression of HMGB1 or c-IAP2 protein and other variables (such as age, gender and viral infection) (Table 2).

\subsection{Upregulation of HMGB1 and c-IAP2 Proteins at the Transcriptional Level in HCC Tissues}

To further assess the overexpression of HMGB1 and cIAP2 mRNA and proteins in HCC tissue samples, we performed qRT-PCR in fresh HCC and paired para-tumor tissue samples. Expression of HMGB1 mRNA was 2.209 fold higher in HCC tissue than paired para-tumor tissue $(t=5.976, P<0.01$, Figure $3 \mathrm{~A})$, while expression of c-IAP2 mRNA was 2.769 fold higher in tumor tissue than paired para-tumor tissue samples $(t=9.507, \mathrm{P}<0.01$, Figure $3 \mathrm{~B})$. These data indicated that upregulation of these two proteins was at the transcriptional level. 
Bi MR et al.

Figure 1. Immunohistochemical Staining of HMGB1 and c-IAP2 in HCC and Para-Tumor Tissue Samples
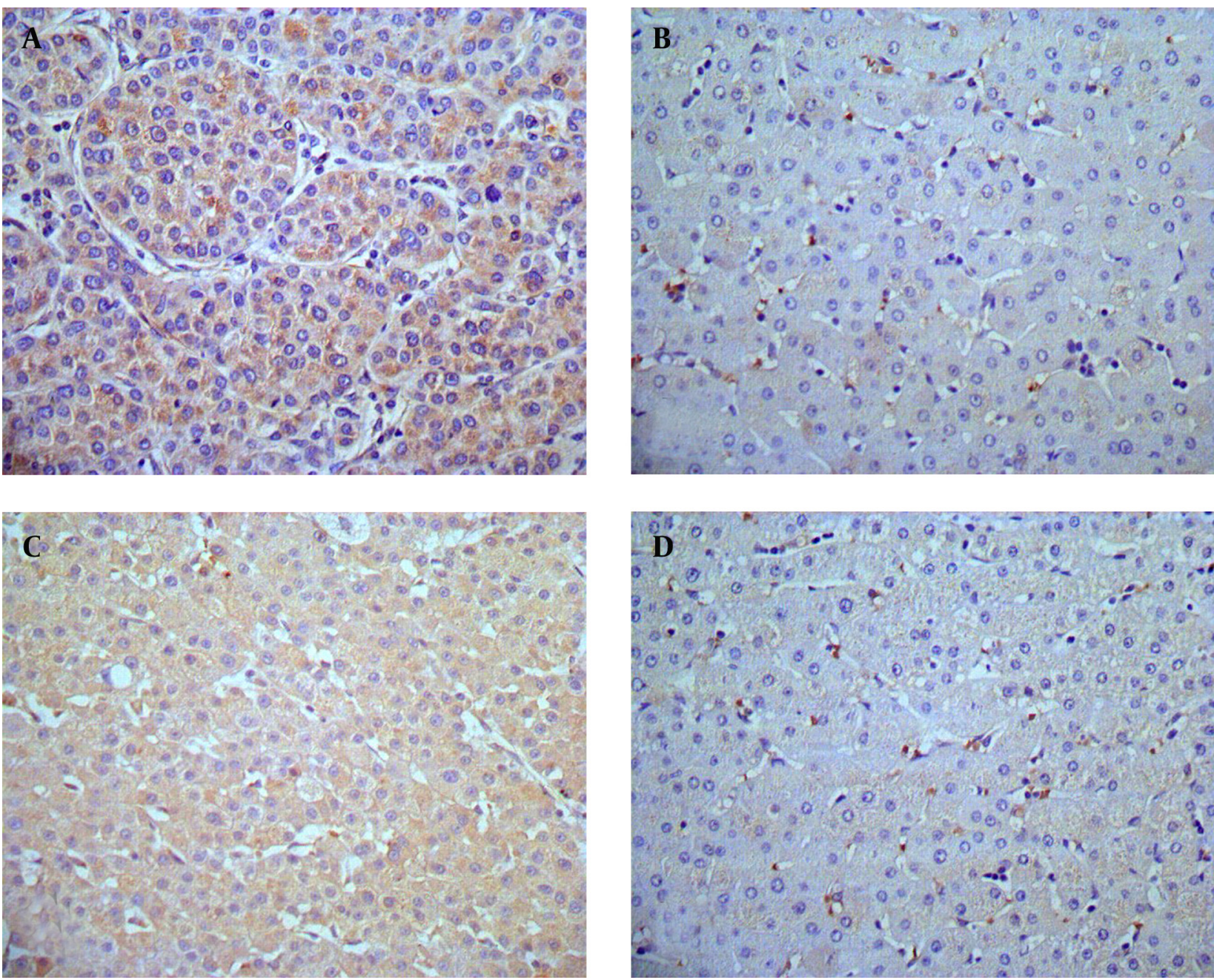

(A) High expression of HMGB1 in HCC tissue samples, HMGB1 immunostaining was predominantly localized in the cytoplasm of HCC cells (× 400). (B) Weak expression of HMGB1 protein in the para-tumor tissue samples ( $\times 400)$. (C) High expression of c-IAP2 protein in HCC tissue samples. C-IAP2 immunostaining mainly occurs in the cytoplasm of tumor cells $(\times 400)$. (D) Weak expression of c-IAP2 in para-tumor tissue samples $(\times 400)$.

Table 1. HMGB1 and c-IAP2 Expression in Tumor Tissue and Paired Para-Tumor Tissue of all 68 HCC Cases Fresh Tissue Samples

\begin{tabular}{|c|c|c|c|c|c|c|c|c|c|c|}
\hline \multirow{2}{*}{$\begin{array}{l}\text { Tissue } \\
\text { type }\end{array}$} & \multicolumn{4}{|c|}{ HMGB1 } & \multirow{2}{*}{$\begin{array}{c}\text { Positive } \\
\text { Rate, \% }\end{array}$} & \multicolumn{4}{|c|}{ c-IAP2 } & \multirow{2}{*}{$\begin{array}{c}\text { Positive } \\
\text { Rate,\% }\end{array}$} \\
\hline & - & + & ++ & +++ & & - & + & ++ & +++ & \\
\hline Tumor & 10 & 14 & 19 & 25 & $85.3^{a}$ & 12 & 18 & 17 & 21 & $82.4^{\mathrm{b}}$ \\
\hline $\begin{array}{l}\text { Para- } \\
\text { tumor }\end{array}$ & 46 & 11 & 9 & 2 & 32.3 & 49 & 10 & 8 & 1 & 27.9 \\
\hline
\end{tabular}

a $\chi^{2}=46.104, \mathrm{P}<0.01$.

$\mathrm{b}^{2}=46.335, \mathrm{P}<0.01$. 
A
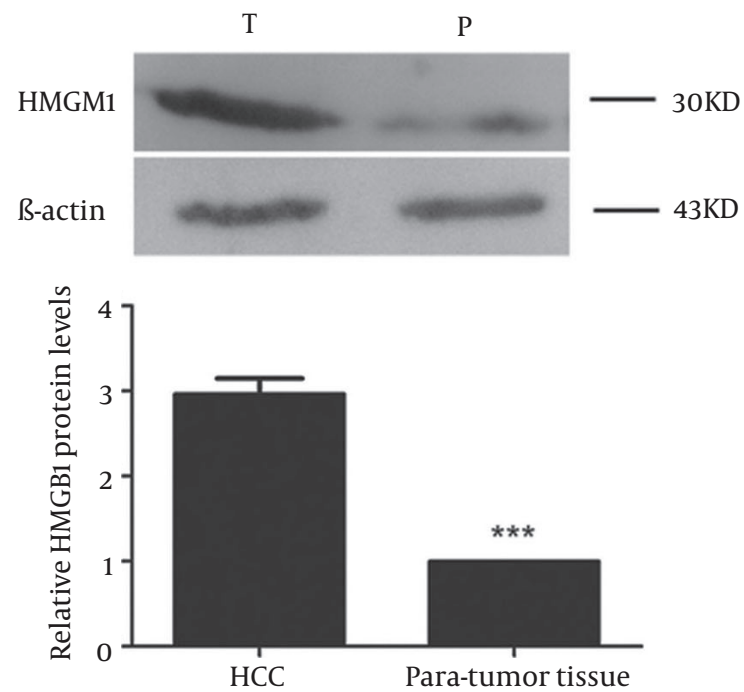

B
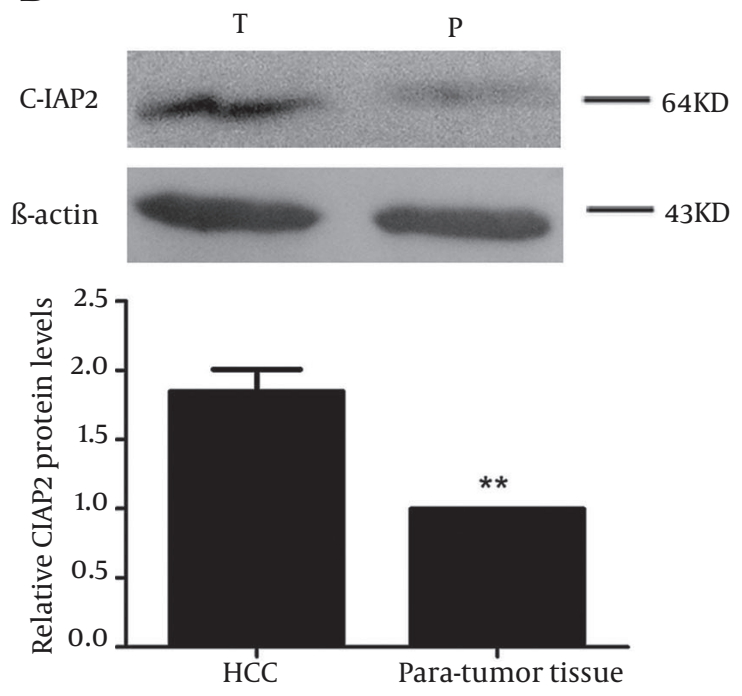

(A) Representative Western blot data on HMGB1 expression in cases and a chart on the relative expression levels of HMGB1 for tumor and para-tumor samples. (B) Representative Western blot data on c-IAP2 expression in cases and a chart on the relative expression levels of HMGB1 for tumor and paratumor samples. $\beta$-actin served as an internal control. Lane T corresponds to the expression of HMGB1 and c-IAP2 in HCC samples and lane P corresponds to the expression of HMGB1 and c-IAP2 in paired para-tumor tissue samples.

\begin{tabular}{|c|c|c|c|c|c|c|c|}
\hline Variables & Cases $(n=68)$ & HMGB1 $(n=58)$ & $\chi^{2}$ & PValue & $\operatorname{cIAP}-2(n=56)$ & $\chi^{2}$ & PValue \\
\hline Age & & & 1.912 & $>0.05$ & & 0.0277 & $>0.05$ \\
\hline$<60$ & 55 & $49(89)$ & & & $46(84)$ & & \\
\hline$\geq 60$ & 13 & $9(69)$ & & & $10(77)$ & & \\
\hline Gender & & & 0.140 & $>0.05$ & & 0.0005 & $>0.05$ \\
\hline Male & 54 & $47(87)$ & & & $44(81)$ & & \\
\hline Female & 14 & $11(78)$ & & & $12(86)$ & & \\
\hline Viral infection & & & 3.097 & $>0.05$ & & 1.36 & $>0.05$ \\
\hline $\operatorname{HBV}(+)$ & 39 & $35(89)$ & & & $34(87)$ & & \\
\hline $\mathrm{HCV}(+)$ & 20 & $17(85)$ & & & $15(75)$ & & \\
\hline Other virus & 9 & $6(67)$ & & & $7(78)$ & & \\
\hline AFP level, $\mu \mathrm{g} / \mathrm{L}$ & & & 4.83 & $<0.05$ & & 9.998 & $<0.05$ \\
\hline$<400$ & 36 & $27(75)$ & & & $24(67)$ & & \\
\hline$\geq 400$ & 32 & $31(97)$ & & & $31(97)$ & & \\
\hline Tumor numbers & & & 4.225 & $<0.05$ & & 3.353 & $>0.05$ \\
\hline Single & 46 & $36(78)$ & & & $35(76)$ & & \\
\hline Multiple & 22 & $22(100)$ & & & $21(95)$ & & \\
\hline Tumor size, $\mathrm{cm}$ & & & 10.748 & $<0.05$ & & 9.862 & $<0.05$ \\
\hline$<3$ & 29 & $20(69)$ & & & $19(66)$ & & \\
\hline$\geq 3$ & 39 & $38(97)$ & & & $37(95)$ & & \\
\hline TNM stage & & & 7.0584 & $<0.05$ & & 8.228 & $<0.05$ \\
\hline I & 20 & $14(70)$ & & & $13(65)$ & & \\
\hline II & 29 & $25(86)$ & & & $24(83)$ & & \\
\hline III & 19 & $19(100)$ & & & $19(100)$ & & \\
\hline
\end{tabular}

\footnotetext{
a Abbreviations: HBV, hepatitis B virus; HCV, hepatitis C virus; AFP, alpha-fetoprotein.

b Data are presented as (N. \%).
} 
A

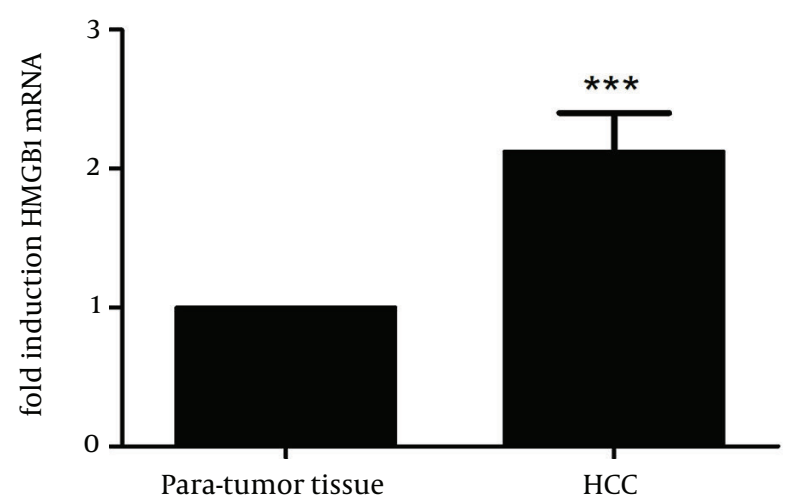

B

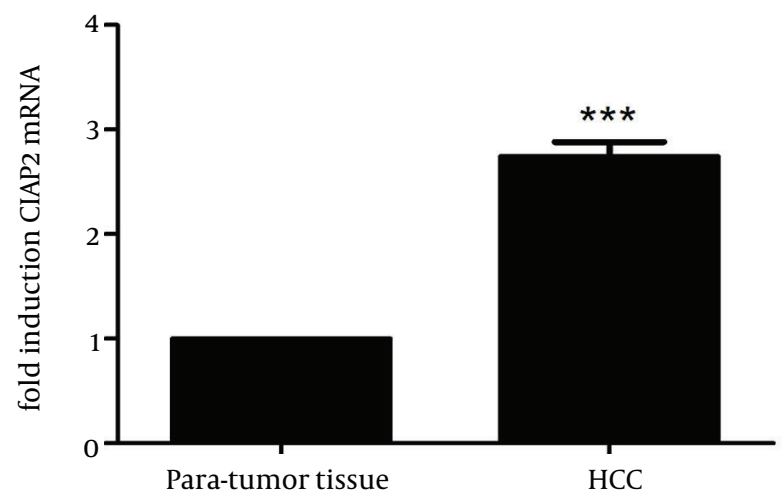

(A) qRT-PCR analysis of HMGB1 mRNA. The expression of HMGB1 mRNA was 2.209 fold higher in HCC tissue than paired para-tumor tissue $(\mathrm{t}=5.976$, $\mathrm{P}<$ 0.01), (B) qRT-PCR analysis of c-IAP2 mRNA. The expression of c-IAP2 mRNA was 2.769 fold higher in tumor tissue than paired para-tumor tissue samples (t $=9.507, \mathrm{P}<0.01)$. Data are expressed as mean \pm SD from three independent experiments. $\quad \mathrm{P}<0.01$ compared to the para-tumor tissue samples.

Table 3. Association of HMGB1 and c-IAP2 Proteins in HCC Tissue Samples ${ }^{\mathrm{a}}$

\begin{tabular}{lccccc}
\hline HMGB1 & \multicolumn{3}{c}{ C-IAP2 } & \multicolumn{2}{c}{ Total } \\
\hline & - & + & ++ & +++ & \\
\hline- & 5 & 3 & 1 & 1 & 10 \\
+ & 3 & 2 & 3 & 4 & 12 \\
++ & 3 & 3 & 5 & 8 & 19 \\
+++ & 1 & 3 & 9 & 14 & 27 \\
Total & 12 & 11 & 18 & 27 & 68 \\
\hline a Spearman's rank correlation test, rs $=0.878, \mathrm{P}<001$. & &
\end{tabular}

\subsection{Association of HMGB1 and c-IAP2 Protein Ex- pression in HCC Tissues}

We associated the expression of HMGB1 and c-IAP2 proteins in HCC tissue samples using Spearman's test, since HMGB1 may act as an oncoprotein to inhibit cell apoptosis (34), while c-IAP2 is a key antiapoptotic factor. Using immunohistochemical analysis, 46 of 68 HCC cases showed high expression of HMGB1 in tumor tissue samples, 45 of 68 HCC cases showed a high expression of c-IAP2 in tumor tissue samples, while 36 of 68 HCC cases showed both high expression of HMGB1 and c-IAP2 in tumor tissue samples (Table 3, rs $=0.878, \mathrm{P}<0.01$ ), indicating that high expression of HMGB1 protein was significantly associated with enhanced levels of c-IAP2 protein in HCC tissue samples.

\section{Discussion}

In the present study, we detected expression of HMGB1 and c-IAP2 mRNA and proteins in HCC tissue and para- tumor tissue samples. We found an upregulation of both HMGB1 and c-IAP2 mRNA and proteins in HCC tissue samples compared to para-tumor tissue samples. Nevertheless, some of para-tumor tissue samples expressed a low level of these proteins, which indicates that para-tumor tissue may be really normal tissues, which could have a field of carcinogenesis effects and second para-tumour tissues usually had multiple lesions, such as hepatitis, cirrhosis, premalignant lesion of HCC. Therefore, all of these could contribute to low expression of these two proteins in para-tumour tissues. Upregulation of HMGB1 protein was associated with tumor multiplicity, tumor size, AFP level and advanced TNM stages, while expression of c-IAP2 was associated with tumor size, AFP level and advanced TNM stage. Moreover, expression of HMGB1 protein was associated with upregulation of c-IAP2 expression in HCC tissues. These data suggest that altered expression of both HMGB1 and c-IAP2 proteins was associated with HCC development and tumor progression. Further studies would investigate whether targets of these two proteins can be used as a novel therapeutic strategy in HCC treatment. Our current immunohistochemical data showed that HMGB1 was mostly localized at the cytosol of tumor cells, which raised a question why this nuclear protein appears in the cytoplasm, but not in the nuclei of tumor cells. Indeed, a previous review publication discussed that the presence of HMGB1 protein in the nucleus depends on posttranslational modifications. When the protein is not acetylated, it stays in the nucleus, but hyperacetylation on lysine residues causes it to translocate into the cytosol (9). Furthermore, HMGB1 protein is also secreted by immune cells, including monocytes, macrophages and dendritic cells (9). In addition, our current data was consistent with previous studies showing upregulated HMGB1 levels in HCC tissues compared to 
para-tumor tissues (35-37). Previous studies demonstrated the ability of HMGB1 protein to support tumor growth and metastasis through its function as an extracellular ligand to induce cell proliferation $(13,38-40)$ or through its pro-inflammatory properties as a cytokine (14). Alternatively, HMGB1 has the ability to suppress apoptosis (14, 40). A previous study demonstrated that overexpression of HMGB1 protein inhibited Bak-induced cell death by inhibition of caspase- 9 activation (23). Most caspase family members are promoters or effectors of apoptosis, playing important roles in the process of apoptosis $(23,29)$. Caspase activity can be regulated by IAP proteins, especially, c-IAP2, which is known to directly bind to caspase-3 and caspse-7 proteins and inhibit their activity and activation of pro-caspase-9 proteins. In the current study, we analyzed the expression of c-IAP2 mRNA and protein and found that expression of HMGB1 protein was associated with upregulation of c-IAP2 protein in HCC tissues. Overexpression of c-IAP2 protein has been found in a variety of human cancers and associated with drug resistance and recurrence of different human cancers $(31,32,41)$. In the current study, we found that upregulation of c-IAP2 protein in HCC tissues was associated with tumor size, AFP level and advanced TNM stages. These data were consistent with a previous study in colon cancer (23). In the recent years, there has been increasing interest in the role of HMGB1 in HCC. For example, Cheng et al. (37) reported an association between serum HMGB1 level and clinicopathological features of HCC patients, i.e. higher serum HMGB1 level was associated with bigger tumor size, poor tumor differentiation and advanced TNM stages. Jiang et al. (26) showed that overexpression of HMGB1 in tumor tissue samples, rather than para-tumor tissue samples, was associated with advanced TNM stage, vascular invasion and capsule invasion of HCC. Recently, Liu et al. (27, 42) showed that expression of HMGB1 was significantly associated with incomplete tumor encapsulation and advanced TNM stages. In the current study using both fresh tissues samples and paraffin blocks from 68 HCC patients, we demonstrated that expression of HMGB1 was significantly associated with tumor multiplicity and size, AFP level and advanced TNM stages, while expression of c-IAP2 was associated with tumor size, AFP level and advanced TNM stage. The current study found an association between the expression of HMGB1 and cIAP2 proteins in HCC, suggesting that c-IAP2 could mediate the effects of HMGB1 on inhibition of HCC apoptosis and promotion of HCC progression. We also showed that upregulation of HMGB1 and c-IAP2 was at the transcriptional level. Further studies are warranted to target these proteins as novel therapeutic strategies in the treatment of HCC patients and investigate how HMGB1 regulate cIAP2 expression in HCC cells.

\section{Acknowledgements}

We would like to thank Prof. Zhaohua Zhong from the Department of Microbiology, Harbin Medical University
(Harbin, China) to help in discussing the manuscript. This work was supported in part by a grant from the Ma Ying Ji Research Fund.

\section{Authors' Contribution}

Ma and Bi performed the molecular genetic studies, participated in sequence alignment and drafted the manuscript. Bi and Yang performed the immunoassays. $\mathrm{Bi}$ and Zhu participated in the sequence alignment. Bi and Yan and Chen participated in design of the study and performed the statistical analysis. Wang conceived of the study, participated in design and coordination and helped to draft the manuscript. All authors read and approved the final version.

\section{Finding/Support}

This work was supported in part by a grant from the Ma Ying Ji Research Fund.

\section{References}

1. El-Serag HB, Rudolph KL. Hepatocellular carcinoma: epidemiology and molecular carcinogenesis. Gastroenterology. 2007;132(7):2557-76.

2. Poon D, Anderson BO, Chen LT, Tanaka K, Lau WY, Van Cutsem E, et al. Management of hepatocellular carcinoma in Asia: consensus statement from the Asian Oncology Summit 2009. Lancet Oncol. 2009;10(11):1111-8.

3. Rampone B, Schiavone B, Confuorto G. Current management of hepatocellular cancer. Curr Oncol Rep. 2010;12(3):186-92.

4. Kumar V, Fausto N, Abbas A editors. : Saunders. Robbins \& Cotran Pathologic Basis of Disease . 7th ed.

5. Yan YP, Su HX, Ji ZH, Shao ZJ, Pu ZS. Epidemiology of Hepatitis B Virus Infection in China: Current Status and Challenges.J Clin Trans Hepatol. 2014;2(1):15-21.

6. Wang XW, Hussain SP, Huo TI, Wu CG, Forgues M, Hofseth LJ, et al. Molecular pathogenesis of human hepatocellular carcinoma. Toxicology. 2002;181-182:43-7.

7. Cha C, Dematteo RP. Molecular mechanisms in hepatocellular carcinoma development. Best Pract Res Clin Gastroenterol. 2005;19(1):25-37.

8. Llovet JM, Burroughs A, Bruix J. Hepatocellular carcinoma. Lancet. 2003;362(9399):1907-17.

9. Klune JR, Dhupar R, Cardinal J, Billiar TR, Tsung A. HMGB1: endogenous danger signaling. Mol Med. 2008;14(7-8):476-84.

10. Ulloa L, Messmer D. High-mobility group box 1(HMGB1) protein: friend and foe. Cytokine Growth Factor Rev. 2006;17(3):189-201.

11. Lotze MT, Tracey KJ. High-mobility group box 1 protein (HMGB1): nuclear weapon in the immune arsenal. Nat Rev Immunol. 2005;5(4):331-42.

12. Campana L, Bosurgi L, Rovere-Querini P. HMGB1: a two-headed signal regulating tumor progression and immunity. Curr Opin Immunol. 2008;20(5):518-23.

13. Tang D, Kang R, Livesey KM, Cheh CW, Farkas A, Loughran P, et al. Endogenous HMGB1 regulates autophagy. J Cell Biol. 2010;190(5):881-92.

14. Gong H, Zuliani P, Komuravelli A, Faeder JR, Clarke EM. Analysis and verification of the HMGB1 signaling pathway. BMC Bioinformatics. 2010;11 Suppl 7:S10.

15. Kostova N, Zlateva S, Ugrinova I, Pasheva E. The expression of HMGB1 protein and its receptor RAGE in human malignant tumors. Mol Cell Biochem. 2010;337(1-2):251-8.

16. Sims GP, Rowe DC, RietdijkST, Herbst R, Coyle AJ.HMGB1 and RAGE in inflammation and cancer. Annu Rev Immunol. 2010;28:367-88.

17. Flohr AM, Rogalla P, Meiboom M, Borrmann L, Krohn M, ThodeHalle $\mathrm{B}$, et al. Variation of HMGB1 expression in breast cancer. Anticancer Res. 2001;21(6A):3881-5. 
18. Brezniceanu ML, Volp K, Bosser S, Solbach C, Lichter P, Joos S, et al. HMGB1 inhibits cell death in yeast and mammalian cells and is abundantly expressed in human breast carcinoma. FASEB $J$. 2003;17(10):1295-7.

19. Poser I, Bosserhoff AK. Transcription factors involved in development and progression of malignant melanoma. Histol Histopathol.2004;19(1):173-88.

20. Poser I, Golob M, Buettner R, Bosserhoff AK. Upregulation of HMG1 leads to melanoma inhibitory activity expression in malignant melanoma cells and contributes to their malignancy phenotype. Mol Cell Biol. 2003;23(8):2991-8.

21. Choi YR, Kim H, Kang HJ, Kim NG, Kim JJ, Park KS, et al. Overexpression of high mobility group box 1 in gastrointestinal stromal tumors with KIT mutation. Cancer Res. 2003;63(9):2188-93.

22. Meyer A, Staratschek-Jox A, Springwald A, Wenk H, Wolf J, Wickenhauser $C$, et al. Non-Hodgkin lymphoma expressing high levels of the danger-signalling protein HMGB1. Leuk Lymphoma. 2008;49(6):1184-9.

23. Volp K, Brezniceanu ML, Bosser S, Brabletz T, Kirchner T, Gottel D, et al. Increased expression of high mobility group box 1 (HMGB1) is associated with an elevated level of the antiapoptotic c-IAP2 protein in human colon carcinomas. Gut. 2006;55(2):234-42.

24. Ohmori H, Luo Y, Kuniyasu H. Non-histone nuclear factor HMGB1 as a therapeutic target in colorectal cancer. Expert Opin Ther Targets. 2011;15(2):183-93.

25. Yan W, Chang Y, Liang X, Cardinal JS, Huang H, Thorne SH, et al. High-mobility group box 1 activates caspase-1 and promotes hepatocellular carcinoma invasiveness and metastases. Hepatology. 2012;55(6):1863-75.

26. Jiang W, Wang Z, Li X, Li J, Huang Y, Fan X, et al. Reduced highmobility group box 1 expression induced by RNA interference inhibits the bioactivity of hepatocellular carcinoma cell line HCCLM3. Dig Dis Sci. 2012;57(1):92-8.

27. Liu F, Zhang Y, Peng Z, Gao H, Xu L, Chen M. High expression of high mobility group box 1 (hmgb1) predicts poor prognosis for hepatocellular carcinoma after curative hepatectomy. J Transl Med. 2012;10:135.

28. Guo ZS, Liu Z, Bartlett DL, Tang D, Lotze MT. Life after death: targeting high mobility group box 1 in emergent cancer therapies. Am J Cancer Res. 2013;3(1):1-20.

29. Wang CY, Mayo MW, Korneluk RG, Goeddel DV, Baldwin AS, Jr.. NF-kappaB antiapoptosis: induction of TRAF1 and TRAF2 and C-IAP1 and C-IAP2 to suppress caspase- 8 activation. Science. 1998;281(5383):1680-3.
30. Varfolomeev E, Goncharov T, Fedorova AV, Dynek JN, Zobel K, Deshayes K, et al. c-IAP1 and c-IAP2 are critical mediators of tumor necrosis factor alpha (TNFalpha)-induced NF-kappaB activation. J Biol Chem. 2008;283(36):24295-9.

31. de Graaf AO, van Krieken JH, Tonnissen E, Wissink W, van de Locht L, Overes I, et al. Expression of C-IAP1, C-IAP2 and SURVIVIN discriminates different types of lymphoid malignancies. Br J Haematol. 2005;130(6):852-9.

32. Xia L, Xue XZ. Immunohistochemical study of NF-kappaB p65 c-IAP2 and caspase-3 expression in cervical cancer. Oncol Lett. 2012;3(4):839-44

33. Tang D, Lotze MT, Kang R, Zeh HJ. Apoptosis promotes early tumorigenesis. Oncogene. 2011;30(16):1851-4.

34. Jiang W, Wang Z, Li X, Fan X, Duan Y. High-mobility group box 1 is associated with clinicopathologic features in patients with hepatocellular carcinoma. Pathol Oncol Res. 2012;18(2):293-8.

35. Kohles N, Nagel D, Jungst D, Stieber P, Holdenrieder S. Predictive value of immunogenic cell death biomarkers HMGB1, sRAGE, and DNase in liver cancer patients receiving transarterial chemoembolization therapy. Tumour Biol. 2012;33(6):2401-9.

36. Dong YD, Cui L, Peng CH, Cheng DF, Han BS, Huang F. Expression and clinical significance of HMGB1 in human liver cancer: Knockdown inhibits tumor growth and metastasis in vitro and in vivo. Oncol Rep. 2013;29(1):87-94.

37. Cheng BQ, Jia CQ, Liu CT, Lu XF, Zhong N, Zhang ZL, et al. Serum high mobility group box chromosomal protein 1 is associated with clinicopathologic features in patients with hepatocellular carcinoma. Dig Liver Dis. 2008;40(6):446-52.

38. Tang D, Kang R, Zeh HJ, 3rd., Lotze MT. High-mobility group box 1 and cancer. Biochim Biophys Acta. 2010;1799(1-2):131-40.

39. Peinado H, Lavotshkin S, Lyden D. The secreted factors responsible for pre-metastatic niche formation: old sayings and new thoughts. Semin Cancer Biol. 2011;21(2):139-46.

40. Tang D, Kang R, Cheh CW, Livesey KM, Liang X, Schapiro NE, et al. HMGB1 release and redox regulates autophagy and apoptosis in cancer cells. Oncogene. 2010;29(38):5299-310.

41. Song Q, Wang G, Chu Y, Zhou L, Jiang M, He Q, et al. TNF-alpha up-regulates cellular inhibitor of apoptosis protein 2 (c-IAP2) via c-Jun N-terminal kinase (JNK) pathway in nasopharyngeal carcinoma. Int Immunopharmacol. 2013;16(2):148-53.

42. Al Hamoudi W, Khalaf H, Allam N, Al Sebayel M. Coincidental occurrence of hepatocellular carcinoma and cholangiocarcinoma (collision tumors) after liver transplantation: a case report. Hepat Mon. 2012;12(10 HCC). 